\title{
Choice architecture to promote fruit and vegetable purchases by families participating in the Special Supplemental Program for Women, Infants, and Children (WIC): randomized corner store pilot study
}

\author{
Anne N Thorndike ${ }^{1,2, *}$, Oliver-John M Bright ${ }^{1}$, Melissa A Dimond ${ }^{3}$, Ronald Fishman ${ }^{3}$ and \\ Douglas E Levy ${ }^{2,4}$ \\ 'General Medicine Division, Department of Medicine, Massachusetts General Hospital, 50 Staniford Street, \\ 9th Floor, Boston, MA 0211 4, USA: ${ }^{2}$ Harvard Medical School, Boston, MA, USA: ${ }^{3}$ Center for Community Health \\ Improvement, Massachusetts General Hospital, Boston, MA, USA: ${ }^{4}$ Mongan Institute for Health Policy, Department of \\ Medicine, Massachusetts General Hospital, Boston, MA, USA
}

Submitted 14 June 2016: Final revision received 15 September 2016: Accepted 12 October 2016: First published online 28 November 2016

\begin{abstract}
Objective: To conduct a pilot study to determine if improving the visibility and quality of fresh produce (choice architecture) in corner stores would increase fruit/ vegetable purchases by families participating in the Special Supplemental Nutrition Program for Women, Infants, and Children (WIC).

Design: Six stores were randomly assigned to choice architecture intervention or control. Store-level WIC sales data were provided by the state. Primary outcomes were WIC fruit/vegetable voucher and non-fruit/vegetable voucher sales, comparing trends from baseline (December 2012-October 2013) with the five-month intervention period (December 2013-April 2014). Secondary outcomes were differences in customer self-reported fruit/vegetable purchases between baseline and end of the intervention.

Setting: Chelsea, MA, USA, a low-income urban community.

Subjects: Adult customers ( $n$ 575) completing store exit interviews.

Results: During baseline, WIC fruit/vegetable and non-fruit/vegetable sales decreased in both intervention and control stores by $\$$ US $16 /$ month. During the intervention period, WIC fruit/vegetable sales increased in intervention stores by \$US $40 /$ month but decreased in control stores by \$US $23 /$ month (difference in trends: \$US 63/month; 95\% CI 4, 121 \$US/month; $P=0 \cdot 036$ ); WIC non-fruit/ vegetable sales were not different $(P=0 \cdot 45)$. Comparing baseline and intervention-period exit interview responses by customers participating in WIC ( $n$ 134), intervention store customers reported increased fruit/vegetable purchases compared with control store customers (18v. $-2 \%$ ), but this did not achieve statistical significance $(P=0 \cdot 11)$.

Conclusions: Placement of fruits/vegetables near the front of corner stores increased purchase of produce by customers using WIC. New policies that incentivize stores to stock and prominently display good-quality produce could promote healthier food choices of low-income families.
\end{abstract}

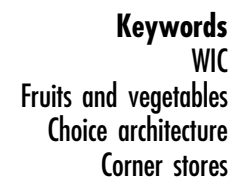

Disparities in obesity and related health outcomes among low-income and minority populations are largely driven by differences in dietary intake ${ }^{(1)}$. Efforts to improve healthy diet in low-income communities have focused on increasing access to healthy foods ${ }^{(2,3)}$. Despite strong epidemiological evidence for the association between poor access to healthy foods and obesity ${ }^{(4-7)}$, recent studies suggest that improving access alone (i.e. new neighbourhood supermarkets or adding healthy items to store inventories) may not translate into healthier diets and lower rates of obesity ${ }^{(8-10)}$. New integrated policy and community-based approaches for promoting healthy eating are needed to reduce disparities ${ }^{(11-13)}$.

The Special Supplemental Nutrition Program for Women, Infants, and Children (WIC) provides food assistance and education to promote healthy nutrition for infants, children younger than 5 years of age, and pregnant and postpartum women. Two-thirds of WIC 
participants are living at or below the federal poverty level and $45 \%$ are Hispanic/Latino ${ }^{(14)}$. In 2009, the US Department of Agriculture revised WIC food packages to improve dietary intake and promote healthy weight among families, including providing cash-value vouchers (\$US 10 for pregnant and postpartum women; \$US 6 for children under 5 years) to purchase eligible fresh, frozen or canned fruits and vegetables. Several studies have demonstrated that the WIC package changes resulted in increased availability of healthy foods in WIC-certified stores $^{(15-18)}$. Although one study demonstrated that the purchase of fruits/vegetables increased ${ }^{(19)}$, results from other studies assessing the influence of the WIC changes on food purchases and dietary intake, particularly fruits/ vegetables, have been mixed ${ }^{(20-23)}$.

In low-income, urban neighbourhoods, many corner stores accept WIC and are a source of groceries ${ }^{(4,5,24)}$. The most prominent items displayed in corner stores, usually near the store entrance and checkout counter, include unhealthy snacks, sugar-sweetened beverages and baked goods, and these items comprise a large proportion of store sales ${ }^{(25-29)}$. Fresh fruits/vegetables have limited shelf space, are located in the back of the stores and are often of poor quality ${ }^{(17,30)}$.

In the present study, we use the term choice architecture, as defined by Hollands et al., to mean interventions that involve altering the properties or placement of objects or stimuli within micro-environments with the intention of changing health-related behavior ${ }^{\text {(31) }}$. Research has demonstrated that choice architecture interventions that place healthy foods and beverages in highly visible and convenient positions are associated with increased sales or selection of these items, including fruits/ vegetables $^{(32-35)}$. Most studies testing the impact of choice architecture on food choices have taken place in worksite or school cafeterias and have demonstrated that employees and students are more likely to choose healthier items when they are placed at eye level or convenient locations ${ }^{(32-35)}$. However, little is known about whether choice architecture influences healthy choices in retail settings by people from low-income communities, particularly among those who participate in government food assistance programmes such as WIC. We conducted a randomized, controlled study of six corner stores in a low-income, Latino community to determine if a choice architecture intervention to increase the visibility and quality of fresh produce in corner stores would result in increased redemption of the WIC fruit/vegetable vouchers at intervention stores compared with control stores.

\section{Methods}

\section{Setting}

The present study was conducted in Chelsea, MA, USA, a city located on the northern border of Boston with a population of 37000 people, of which $62 \%$ are Hispanic/ Latino and $27 \%$ live below the poverty level. In 2011, a comprehensive survey of all stores in Chelsea that sold food found a total of forty-nine stores, including thirty-six corner stores, three supermarkets (two large and one medium-sized), seven convenience stores and three pharmacies.

\section{Store recruitment and randomization}

In the spring of 2013, we recruited corner stores in Chelsea. To be eligible, stores had to be located in predominantly low-income neighbourhoods, accept both WIC vouchers and Supplemental Nutrition Assistance Program (SNAP) Electronic Benefits Transfer cards, and be willing to be randomized. All WIC-certified stores fulfilled the WIC mandatory minimum inventory requirements. The minimum requirements for stocking fruits/vegetables were: two types of fruits (one type must be fresh) and two types of vegetables (one type must be fresh).

The plan was to enrol six stores that met eligibility criteria and that agreed to be randomized. Because it was a pilot study, this sample size was determined by available resources and not an a priori power calculation. Store owners or managers were approached individually by a study staff member working full-time in the Chelsea community and fluent in Spanish, who informed them that they would receive a payment of \$US 500 every 3 months (total of \$US 1500 per store) if they agreed to participate in the study. A total of fourteen corner stores were eligible (located in Chelsea and accepted WIC and SNAP) and were approached to participate in the study. Eight store owners or managers declined participation because they were not interested in being randomized and participating in a research study. Six stores signed a 'memorandum of understanding' to participate. All stores were located within an area of $2.59 \mathrm{~km}^{2}\left(1\right.$ mile $\left.^{2}\right)$. Stores were recruited in May and June 2013, and the intervention stores underwent changes during the month of November 2013. One store received WIC certification the month prior to enrolment, but the other five stores had been participating in WIC for at least a year prior to study enrolment. The intervention period lasted five months, from December 2013 through April 2014.

The six participating stores were matched in pairs based on their monthly total WIC sales. One store in each pair was randomly assigned to receive the intervention. The stores were not told of their assignment until one month prior to implementation of the intervention in November 2013.

\section{Intervention stores}

The purpose of the choice architecture intervention was to increase the visibility and the quality of fresh produce. Study staff worked with each store owner to determine which changes would be feasible and acceptable in the individual store. Depending on individual needs, we 
Table 1 Description of the intervention (supplies, service and consulting) provided to each of the intervention stores

\begin{tabular}{ll}
\hline $\begin{array}{l}\text { Intervention } \\
\text { store }\end{array}$ & Description of intervention \\
\hline Store A & $\begin{array}{l}\text { - Supplies and advice to make fruit/vegetable } \\
\text { displays more visible: purchased new baskets, } \\
\text { risers, containers, tags and clips, and } \\
\text { produce bags }\end{array}$ \\
& - Service job: painted a wall \\
& - Produce consultant: two visits with store owner/ \\
& manager \\
- Supplies and advice to make fruit/vegetable \\
displays more visible: purchased new shelving \\
cart, baskets, containers, tags and clips, and \\
produce bags and holder \\
- Service job: built small shelving display \\
- $\begin{array}{l}\text { Produce consultant: two visits with store owner/ } \\
\text { manager }\end{array}$ \\
- Supplies and advice to make fruit/vegetable \\
displays more visible: purchased new table, \\
baskets, containers, tags and clips, produce bags \\
and holder, and burlap roll
\end{tabular}

provided stores with supplies to improve their produce displays (shelving, baskets, etc.) and one store received a new refrigeration unit (Table 1). Each store owner met at least twice with a 'produce consultant', an individual who managed a large produce department at a high-end Boston-area supermarket. The consultant advised the corner store owners about strategies for stocking and maintaining a higher quality of fresh fruits/vegetables, including: which items should and should not be refrigerated; which items should not be stocked adjacent to each other; and how to identify items that are starting to go bad. Study staff worked with each store to create fresh fruit/ vegetable displays that would be immediately visible and attractive to customers when they entered the store. For example, in one store, a large snack chip rack at the front of the store was replaced with a new shelf rack with baskets of fresh fruits/vegetables. In a second store, a shelf rack with baked goods at the front of the store was replaced by baskets of fresh produce. In a third store, a new refrigerator and a large table with baskets of fresh produce were placed near the entrance of the store. Store owners were responsible for choosing and ordering their own produce.

\section{Control stores}

No changes were made to the three stores assigned to the control arm, but a member of the study staff visited the stores weekly during the study period.

\section{Outcome measures}

WIC sales

The primary outcome of the study was redemption of the WIC fruit/vegetable cash-value vouchers at the study stores. The Massachusetts state WIC office provided aggregate monthly sales data from each of the participating corner stores. The monthly data included the number and total dollar amount for both fruit/vegetable vouchers and non-fruit/vegetable vouchers (for all other WIC items) that were redeemed at each store per month. During the intervention period, two of the study stores were terminated from the WIC programme for violating the terms of the WIC Vendor Agreement. The first terminated store had been assigned to the intervention, and although the violations took place prior to the intervention period, the termination occurred one month after the intervention was implemented. The second store terminated from WIC was a control store, and this termination occurred during month 4 of the intervention period. WIC sales were assessed in these two stores through the last month that they had complete WIC data reported.

\section{Customer exit interviews}

Secondary outcomes were self-reported purchase of fruits/ vegetables by customers exiting the study stores. Exit interviews were conducted after the stores were enrolled but prior to implementation of the intervention (May-September 2013) and during the last two months of the follow-up period (March-April 2014). Study staff interviewed adult customers ( $\geq 18$ years old) after making a purchase. Approximately fifty customers from each store were interviewed on weekdays between 09.00 and 17.00 hours. Interviews were conducted in English or Spanish and included questions about: demographics; reasons for visiting the store; living within three blocks of the store; purchase of fresh fruits/vegetables during the visit to the store; plans to purchase fresh fruits/vegetables prior to entering the store; other places the respondent purchased fruits/vegetables; use of WIC or SNAP; and number of children and adults living in the household.

\section{Statistical analysis}

WIC sales were analysed separately for fruit/vegetable voucher and non-fruit/vegetable voucher purchases. We compared changes in monthly sales trends from the eleven months prior to the intervention (December 2012-October 2013) with the five months after the intervention was implemented (December 2013-April 2014), excluding data from the intervention implementation month itself (November 2013), for the three intervention stores $v$. the three control stores, using generalized leastsquares models with store random effects (random-intercept models). There were no additional covariates in the models. The models assessed trends leading into the intervention month, changes in level and trend following 
the intervention month, and the difference in trend changes following the intervention month for the intervention stores compared with the control stores. This latter term was the effect of interest.

For the exit interviews, we tabulated respondent characteristics and examined differences between intervention and control stores using $\chi^{2}$ statistics or $t$ tests. To address the significant differences in respondent characteristics, we estimated a propensity score assessing the likelihood that a respondent shopped at an intervention $v$. a control store as a function of age, sex, Latino ethnicity, number of adults and children living at home, residence within three blocks of the store and frequency with which the respondent shopped at the store. We assessed differences in the likelihood that interview respondents reported purchasing (or planning to purchase) fresh fruits/vegetables (yes/no) in the pre- $v$. post-intervention periods for respondents shopping at intervention stores compared with control stores. We used a difference-in-differences approach using logistic regression, modelling survey outcomes as a function of indicators for pre/post and intervention/control, as well as their interaction term, quintile of the propensity score and whether the respondent was shopping primarily for food at that particular visit. Models were adjusted for clustering at the store level. $P$ values are based on whether the interaction term was significantly different from 0 . Sub-analyses examined responses for WIC and SNAP participants, separately. All data were analysed in 2015.

\section{Results}

\section{Store characteristics}

The six stores that participated in the study ranged in size from $37 \cdot 2$ to $250 \cdot 8 \mathrm{~m}^{2}$ ( 400 to $2700 \mathrm{ft}^{2}$; Table 2). At baseline, the variety of fresh produce in stores ranged between ten and twenty different types of fruits and three and twenty different types of vegetables, and stores processed between fourteen and 126 WIC fruit/vegetable vouchers per store per month.

\section{WIC sales}

Trends in WIC fruit/vegetable voucher and non-fruit/ vegetable voucher sales during the baseline and intervention periods are shown in the Fig. 1. During the baseline period (December 2012-October 2013), fruit/ vegetable voucher and non-fruit/vegetable voucher sales decreased similarly in both intervention and control stores by an average of $\$$ US $16 /$ month. During the intervention period (December 2013-April 2014), fruit/vegetable voucher sales increased in the intervention stores by \$US $40 /$ month but decreased in the control stores by \$US 23/month (difference in trends: \$US 63/month; $95 \%$ CI 4, $121 \$ \mathrm{US} /$ month; $P=0 \cdot 036$; Fig. 1(a)). Non-fruit/vegetable voucher sales during the intervention period were not different between the intervention and control stores (difference in trends: \$US 265/month; 95\% CI -426 , 955 \$US/month; $P=0 \cdot 45$; Fig. 1(b)). Because most fruit/ vegetable vouchers were redeemed for their full value, trends in the number of fruit/vegetable vouchers redeemed per store per month mirrored changes in total fruit/vegetable voucher sales (difference in trends between intervention and control stores: 8.9 vouchers/month; 95\% CI 0.3 , $17 \cdot 4$ vouchers/month; $P=0 \cdot 04$ ).

\section{Customer exit interviews}

Exit interviews were completed by 295 intervention store customers and 280 control store customers (Table 3). Control store customers were more likely to be Hispanic/ Latino, have more adults and children in the household, live within three blocks of the store, purchase groceries at the store and visit the store more than once weekly. After adjusting for the propensity score, the only significant differences between the control and intervention store customers were increased likelihood of purchasing groceries and decreased likelihood of purchasing snacks, lottery tickets or cigarettes.

Overall, $25 \%(70 / 280)$ of exit interview participants at control stores and $22 \%(64 / 295)$ at intervention stores reported they used WIC, and 38\% (105/280) at control stores and $36 \%(107 / 295)$ at intervention stores reported using SNAP. Among all exit interview participants, there

Table 2 Baseline characteristics of intervention and control stores in Chelsea, MA, USA, December 2012-October 2013

\begin{tabular}{lcccc}
\hline & Store size $\left(\mathrm{m}^{2} / \mathrm{ft}^{2}\right)$ & $\begin{array}{c}\text { No. of fresh } \\
\text { fruit varieties }\end{array}$ & $\begin{array}{c}\text { No. of fresh vegetable } \\
\text { varieties }\end{array}$ & $\begin{array}{c}\text { Mean no. of FVV } \\
\text { redeemed per month† }\end{array}$ \\
\hline Intervention stores & & & & 63 \\
$\quad$ Store A & $87 \cdot 3 / 940$ & 16 & 16 & 112 \\
Store B & $95 \cdot 2 / 1025$ & 10 & 7 & 14 \\
Store C & $148 \cdot 6 / 1600$ & 11 & 3 & 33 \\
Control stores & & & 12 & 126 \\
$\quad$ Store D & $37 \cdot 2 / 400$ & 12 & 20 & 89 \\
$\quad$ Store E & $250 \cdot 8 / 2700$ & 20 & 19 & \\
Store F & $112 \cdot 9 / 1215$ & 18 & & \\
\hline
\end{tabular}

FVV, Special Supplemental Nutrition Program for Women, Infants, and Children (WIC) fruit and vegetable cash-value voucher. †Based on WIC sales from December 2012 to October 2013 for all stores except Store C, which did not become WIC-certified until May 2013 and was based on WIC sales from June 2013 to October 2013. 
(a)

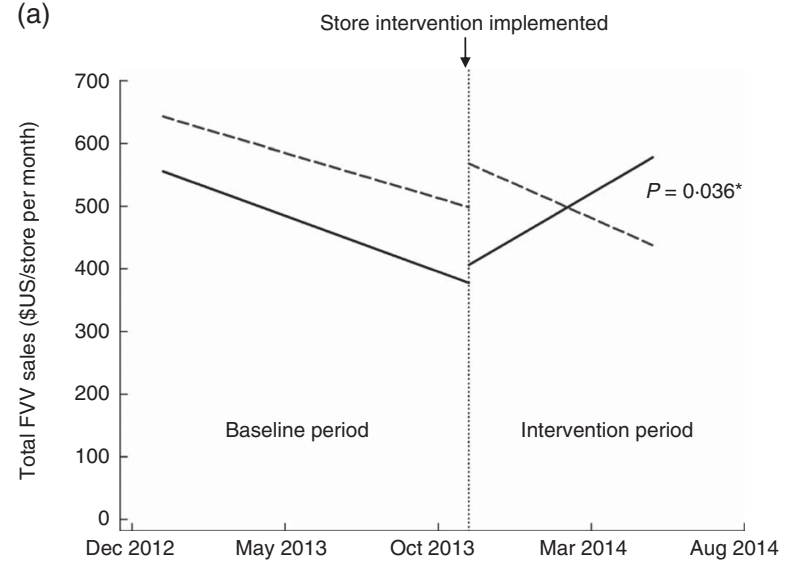

(b)

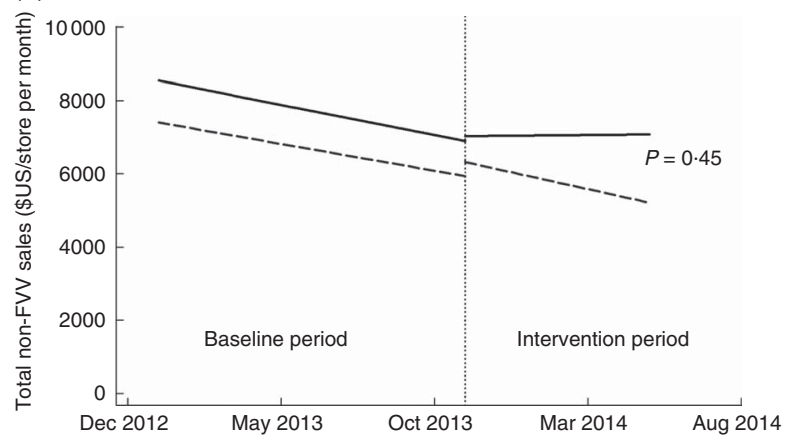

Fig. 1 Trends in (a) WIC fruit and vegetable voucher (FVV) and (b) WIC non-fruit and vegetable voucher (non-FVV) sales at intervention (-) and control (- - - - ) stores in Chelsea, MA, USA, December 2012-April 2014. *Statistical significance at $P<0.05$ for comparison of trend changes for intervention $v$. control stores using generalized least-squares models with store random effects (WIC, Special Supplemental Nutrition Program for Women, Infants, and Children)

was no significant difference between intervention store and control store customers in the difference in purchasing fresh fruits/vegetables between the baseline and intervention periods ( $1 v .-4 \%, P=0.29$ ) or in planning to purchase fresh fruits/vegetables before visiting the store (0 $v .-6 \%, P=0 \cdot 11$; Table 4). However, for customers on SNAP, the difference from baseline to the intervention period in purchasing fresh fruits/vegetables was significantly higher for intervention store customers than for control store customers $(6 v .-15 \%, P=0.007)$ and the difference in planning to purchase fresh fruits/ vegetables was also higher $(3 v .-15 \%, P<0 \cdot 001)$. There were similar but not statistically significant differences for customers on WIC for purchasing (18v. $-2 \%, P=0 \cdot 11)$ and planning to purchase fresh fruits/vegetables (15 v. $-6 \%, P=0 \cdot 17$ ).

\section{Costs of intervention}

All three intervention stores had similar costs for store alterations, including shelving, signage, display baskets and small service jobs such as painting (Store $A=\$$ US 1674;
Store $\mathrm{B}=\$$ US 1380; Store $\mathrm{C}=\$$ US 2032), and for the three visits with the produce consultant (\$US 317 for each store). One store (Store C) also had a refrigeration unit installed at a cost of \$US 5281, including the cost of the refrigeration unit and electrical work to install it.

\section{Discussion}

The present study demonstrates that a simple choice architecture intervention to improve the visibility and quality of fresh produce in corner stores resulted in increased purchase of fruits/vegetables by store customers participating in the WIC programme, based on objective state-level WIC data. Our store exit interview results also suggest that customers who participated in the SNAP programme increased their purchases of fruits/vegetables in the intervention stores. The study results indicate that relatively low-cost, store-level changes increased healthy food purchases by low-income, Latino families on WIC and therefore could help reduce disparities in dietary intake and healthy weight in low-income families.

Although low access to large supermarkets and other food stores has been suggested as an important driver of disparities in healthy eating ${ }^{(4-7)}$, there is no consistent evidence that providing access to large supermarkets will lead to changes in food purchasing patterns and consumption $^{(8,9,36)}$. Many families in low-income, urban communities purchase groceries in small corner stores. Corner stores provide easy accessibility, convenience and familiarity, particularly in a Hispanic/Latino community if the store owners speak Spanish and the store stocks culturally desirable items ${ }^{(24,28,37)}$. Recently, several corner store interventions have been implemented in lowincome communities and have demonstrated increases in the stocking, store-owner reported sales and customer-reported purchases of some targeted healthy items ${ }^{(24,38-42)}$. Thus far, there has been little objective purchasing data available to evaluate whether improving accessibility to healthy items in corner stores is associated with increased sales or consumption of healthy items, particularly by individuals using WIC and SNAP.

In our study, we tested an intervention to assess modifying the choice architecture of corner stores by improving the prominence and quality of fresh produce. In contrast to previous corner store studies, the objective of our study was to rearrange and improve the quality of the products already offered rather than to introduce new products to the store. Research in supermarkets suggests that product placement influences unhealthy purchases, but there is limited research on whether placement alone increases healthy purchases, particularly among low-income populations ${ }^{(43,44)}$. One randomized study of eight supermarkets in a low-income, minority community tested an intervention that placed healthier products in more prominent shelf positions and promoted these items with signage 
Table 3 Demographics and shopping patterns of store customers who participated in exit interviews in Chelsea, MA, USA, June 2013-April 2014

\begin{tabular}{|c|c|c|c|c|}
\hline & $\begin{array}{l}\text { Intervention store } \\
\text { customers ( } n \text { 295) }\end{array}$ & $\begin{array}{c}\text { Control store } \\
\text { customers }(n 280)\end{array}$ & $\begin{array}{c}P \text { value } \\
\text { (unadjusted) }\end{array}$ & $\begin{array}{c}P \text { value } \\
\text { (adjustedt) }\end{array}$ \\
\hline Male (\%) & 47 & 43 & 0.31 & 0.85 \\
\hline \multicolumn{5}{|l|}{ Age category (\%) } \\
\hline $18-39$ years & 55 & 56 & 0.75 & 0.97 \\
\hline $40-59$ years & 37 & 38 & & \\
\hline$\geq 60$ years & 8 & 6 & & \\
\hline Hispanic/Latino ethnicity (\%) & 82 & 92 & 0.001 & 0.29 \\
\hline \multicolumn{5}{|l|}{ No. of adults in household } \\
\hline Mean & $2 \cdot 0$ & 2.4 & $<0.001$ & 0.93 \\
\hline SD & 1.4 & 1.4 & & \\
\hline \multicolumn{5}{|l|}{ No. of children in household } \\
\hline Mean & $1 \cdot 2$ & 1.6 & $<0.001$ & 0.71 \\
\hline SD & 1.3 & 1.2 & & \\
\hline Lives within three blocks of store (\%) & 79 & 88 & 0.005 & 0.79 \\
\hline \multicolumn{5}{|l|}{ Reasons for visiting store (\%) } \\
\hline Groceries & 36 & 64 & $<0.001$ & $<0.001$ \\
\hline Snack & 21 & 13 & 0.017 & 0.002 \\
\hline Beverage & 20 & 17 & 0.44 & 0.23 \\
\hline Lottery ticket or cigarettes & 21 & 7 & $<0.001$ & $<0.001$ \\
\hline Household goods & 2 & 4 & 0.16 & 0.16 \\
\hline Other & 16 & 6 & $<0.001$ & 0.004 \\
\hline \multicolumn{5}{|l|}{ Frequency of visiting store (\%) } \\
\hline$>5$ times per week & 38 & 42 & 0.001 & 0.99 \\
\hline $1-2$ times per week & 45 & 51 & & \\
\hline Once per month & 13 & 5 & & \\
\hline First time at store & 5 & 2 & & \\
\hline
\end{tabular}

$\dagger P$ value adjusted for propensity score assessing the likelihood that a respondent shopped at intervention $v$. control store as a function of: age, sex, Latino ethnicity, numbers of adults and children at home, residence within three blocks of the store and frequency of shopping at the store.

and taste testing ${ }^{(45)}$. The results of that study demonstrated an increase in some of the targeted healthy items (skimmed milk, frozen meals and water) at 6 months, but fruits/vegetables were not included and purchases by customers using government food assistance (i.e. WIC or SNAP) were not assessed. Our study demonstrated that a placement strategy targeting fresh produce increased the sales of fruits and vegetables among low-income families using WIC.

The WIC programme currently only requires stores to stock a minimum of one variety of fresh fruit and one variety of fresh vegetable, but many WIC stores stock a larger number of varieties of fresh produce, as was the case in our study stores (Table 2). Training and educating store owners about stocking and storing fresh produce may prove crucial for reducing rot and product loss. This would benefit customers by making fresh produce look and taste more appealing and store owners by increasing demand for their products, reducing waste and increasing profitability. This positive reinforcement could influence store owners' stocking practices ${ }^{(46)}$.

Objective assessment of purchasing behaviours in corner store interventions is difficult because few stores keep electronic records of their sales ${ }^{(47)}$, but state-level data on WIC fruit/vegetable vouchers provided our study with an objective measurement of sales. However, there are limitations to our study, including a relatively small sample size of six stores from an urban, predominantly Latino community, and findings may not be generalizable to other communities, particularly those that are rural or non-Latino. Larger randomized studies are needed to determine the effectiveness of this intervention in other settings. A second limitation is that WIC fruit/vegetable vouchers could have also been used for certain canned and frozen fruits and vegetables. Although an increase in purchases of canned or frozen fruits/vegetables could have contributed to the increase in WIC fruit/vegetable voucher sales during the intervention, it is unlikely that this would have occurred only in the intervention stores and not in the control stores. Third, it is likely that seasonality influenced purchase of fresh produce. Although seasonality may have influenced overall trends in the use of the fruit/vegetable vouchers, it would not have influenced differences between control and intervention stores. Fourth, two stores were terminated from the WIC programme for violating the WIC vendor agreement. Data from each store were censored the month it was terminated and did not contribute to the analyses after this time. Fifth, although eight stores declined to participate in the study, the reasons for not participating were related to research-related logistics (i.e. not wanting to be randomized) rather than the intervention to improve the fruit/vegetable displays. Finally, we were unable to determine if customers using WIC purchased fruits and vegetables at other stores with either WIC vouchers or cash.

Revisions to the WIC programme in 2009 increased access to fruits/vegetables and was an important first step 
Table 4 Purchase of fresh fruits and vegetables (F/V) by store customers who participated in exit interviews in Chelsea, MA, USA, June 2013-April 2014

\begin{tabular}{|c|c|c|c|c|}
\hline & $\begin{array}{c}\text { Baseline } \\
\text { (Jun-Oct 2013) }\end{array}$ & $\begin{array}{c}\text { Intervention period } \\
\text { (Dec 2013-Apr 2014) }\end{array}$ & Difference & $\begin{array}{c}P \text { valuet for } \\
\text { difference } \\
\text { in differences }\end{array}$ \\
\hline \multicolumn{5}{|c|}{ All survey participants ( $n$ 575) $\ddagger$} \\
\hline \multicolumn{5}{|c|}{ Purchased fresh F/V (\%) } \\
\hline Control stores & 36 & 32 & -4 & \multirow[t]{2}{*}{0.29} \\
\hline Intervention stores & 15 & 16 & 1 & \\
\hline \multicolumn{5}{|c|}{ Planned to purchase $\mathrm{F} / \mathrm{V}(\%)$} \\
\hline Control stores & 38 & 32 & -6 & \multirow[t]{2}{*}{0.11} \\
\hline Intervention stores & 20 & 20 & 0 & \\
\hline \multicolumn{5}{|c|}{ Survey participants on WIC $(n$ 134)§ } \\
\hline Purchased fresh F/V & & & & \\
\hline Control stores & 41 & 39 & -2 & \multirow[t]{2}{*}{0.11} \\
\hline Intervention stores & 18 & 36 & 18 & \\
\hline \multicolumn{5}{|c|}{ Planned to purchase F/V (\%) } \\
\hline Control stores & 45 & 39 & -6 & \multirow[t]{2}{*}{0.17} \\
\hline Intervention stores & 22 & 37 & 15 & \\
\hline \multirow{2}{*}{\multicolumn{5}{|c|}{$\begin{array}{l}\text { Survey participants on SNAP }(n 212) \| \\
\text { Purchased fresh F/V }(\%)\end{array}$}} \\
\hline & & & & \\
\hline Control stores & 41 & 26 & -15 & \multirow[t]{2}{*}{0.007} \\
\hline Intervention stores & 16 & 22 & 6 & \\
\hline \multicolumn{5}{|c|}{ Planned to purchase $\mathrm{F} / \mathrm{V}(\%)$} \\
\hline Control stores & 46 & 31 & -15 & \multirow[t]{2}{*}{$<0.001$} \\
\hline Intervention stores & 21 & 24 & 3 & \\
\hline
\end{tabular}

WIC, Special Supplemental Nutrition Program for Women, Infants, and Children; SNAP, Supplemental Nutrition Assistance Program. $\dagger P$ value adjusted for quintile of propensity score, whether the respondent was shopping primarily for food at that particular visit and for clustering at the store level.

$\ddagger$ No. of participants: control stores, $n 141$ during baseline and $n 139$ during the intervention period; intervention stores, $n 145$ during baseline and $n 150$ during the intervention period.

$\S N$. of participants: control stores, $n 32$ during baseline and $n 38$ during the intervention period; intervention stores, $n 36$ during baseline and $n 28$ during the intervention period.

INNo. of participants: control stores, $n 51$ during baseline and $n 54$ during the intervention period; intervention stores, $n 57$ during baseline and $n 50$ during the intervention period.

for promoting a healthier diet among low-income families. However, growing evidence demonstrates that improving access alone does not guarantee healthier food choices $^{(8-10)}$. The results of our study showed that small changes in the placement and quality of fresh produce prompted increased purchase of fruits/vegetables by WIC customers, and our survey results indicated that customers using SNAP also increased purchase of fresh produce. In the future, the US Department of Agriculture might consider requiring WIC- and SNAP-certified stores to display fruits/vegetables at the front of the stores and to provide education for store owners about stocking and maintaining fresh produce. These types of policies could improve food choices of low-income families and help reduce disparities in dietary intake and obesity.

\section{Acknowledgements}

Acknowledgements: The authors are grateful to the six corner stores in Chelsea, MA for their participation and cooperation during the study. They would also like to thank Mr Ciaran Foley for providing his expertise and advice about fresh produce to the intervention stores. Financial support: This project was supported by the Massachusetts General Hospital Center for Community Health Improvement and by the Nutrition Obesity
Research Center at Harvard (National Institutes of Health grant number P30DK40561). Neither Massachusetts General Hospital nor the National Institutes of Health had any role in the study design; collection, analysis and interpretation of the data; writing of the report; and the decision to submit the report for publication. Conflict of interest: None. Authorship: A.N.T. conceptualized and designed the study, obtained funding for the study, supervised data collection, drafted the initial manuscript, revised the manuscript and approved the final manuscript as submitted. O.-J.M.B. contributed to data analyses and drafting of the initial manuscript; he approved the final manuscript as submitted. M.A.D. helped to conceptualize and design the study, obtain funding and supervise delivery of the intervention; she reviewed and revised the manuscript and approved the final manuscript as submitted. R.F. helped deliver the intervention and supervise data collection; he reviewed and revised the manuscript and approved the final manuscript as submitted. D.E.L. contributed to the design of the study and conducted the study analyses; he reviewed and revised the manuscript and approved the final manuscript as submitted. Ethics of buman subject participation: This study was conducted according to the guidelines laid down in the Declaration of Helsinki. All procedures involving human subjects were approved by the Partners Institutional Review Board (IRB) on 19 November 2012 and found to meet criteria for 
exemption from further IRB review per the regulations found at 45 CFR 46.101(b) (2). Verbal informed consent was obtained from participants, and verbal consent was witnessed and formally recorded.

\section{References}

1. Swinburn BA, Sacks G, Hall KD et al. (2011) The global obesity pandemic: shaped by global drivers and local environments. Lancet 378, 804-814.

2. Keener D, Goodman K, Lowry A et al. (2009) Recommended Community Strategies and Measurements to Prevent Obesity in the United States: Implementation and Measurement Guide. Atlanta, GA: US Department of Health and Human Services, Centers for Disease Control and Prevention.

3. Institute of Medicine (2012) Accelerating Progress in Obesity Prevention: Solving the Weight of the Nation. Washington, DC: The National Academies Press.

4. Inagami S, Cohen DA, Finch BK et al. (2006) You are where you shop: grocery store locations, weight, and neighborhoods. Am J Prev Med 31, 10-17.

5. Morland K, Diez Roux AV \& Wing S (2006) Supermarkets, other food stores, and obesity: the Atherosclerosis Risk in Communities Study. Am J Prev Med 30, 333-339.

6. Powell LM, Auld MC, Chaloupka FJ et al. (2007) Associations between access to food stores and adolescent body mass index. Am J Prev Med 33, 4 Suppl., S301-S307.

7. Larson NI, Story MT \& Nelson MC (2009) Neighborhood environments: disparities in access to healthy foods in the US. Am J Prev Med 36, 74-81.

8. Cummins S, Petticrew M, Higgins C et al. (2005) Large scale food retailing as an intervention for diet and health: quasiexperimental evaluation of a natural experiment. J Epidemiol Community Health 59, 1035-1040.

9. Cummins S, Flint E \& Matthews SA (2014) New neighborhood grocery store increased awareness of food access but did not alter dietary habits or obesity. Health Aff (Millwood) 33, 283-291.

10. Lawman HG, Vander Veur S, Mallya G et al. (2015) Changes in quantity, spending, and nutritional characteristics of adult, adolescent and child urban corner store purchases after an environmental intervention. Prev Med 74, 81-85.

11. Gittelsohn J \& Lee K (2013) Integrating educational, environmental, and behavioral economic strategies may improve the effectiveness of obesity interventions. Appl Econ Perspect Policy 35, 52-68.

12. Hawkes C, Smith TG, Jewell J et al. (2015) Smart food policies for obesity prevention. Lancet 385, 2410-2421.

13. Just DR, Mancino L \& Wansink B (2007) Could Behavioral Economics Help Improve Diet Quality for Nutrition Assistance Program Participants? Economic Research Report no. ERR-43. Washington, DC: US Department of Agriculture, Economic Research Service.

14. Johnson B, Thorn B, McGill B et al. (2013) WIC Participant and Program Characteristics 2012. Final Report. Alexandria, VA: US Department of Agriculture, Food and Nutrition Service.

15. Hillier A, McLaughlin J, Cannuscio CC et al. (2012) The impact of WIC food package changes on access to healthful food in 2 low-income urban neighborhoods. J Nutr Educ Behav 44, 210-216.

16. Andreyeva T, Luedicke J, Middleton AE et al. (2012) Positive influence of the revised Special Supplemental Nutrition Program for Women, Infants, and Children food packages on access to healthy foods. J Acad Nutr Diet 112, 850-858.

17. Zenk SN, Odoms-Young A, Powell LM et al. (2009) Fruit and vegetable availability and selection: federal food package revisions. Am J Prev Med 43, 423-428.
18. Havens EK, Martin KS, Yan J et al. (2012) Federal nutrition program changes and healthy food availability. Am J Prev Med 43, 419-422.

19. Andreyeva $\mathrm{T} \&$ Luedicke J (2015) Incentivizing fruit and vegetable purchases among participants in the Special Supplemental Nutrition Program for Women, Infants, and Children. Public Health Nutr 18, 33-41.

20. Chiasson MA, Findley SE, Sekhobo JP et al. (2013) Changing WIC changes what children eat. Obesity (Silver Spring) 21, $1423-1429$.

21. Kong A, Odoms-Young AM, Schiffer LA et al. (2014) The 18-month impact of special supplemental nutrition program for women, infants, and children food package revisions on diets of recipient families. Am J Prev Med 46, 543-551.

22. Odoms-Young AM, Kong A, Schiffer LA et al. (2014) Evaluating the initial impact of the revised Special Supplemental Nutrition Program for Women, Infants, and Children (WIC) food packages on dietary intake and home food availability in African-American and Hispanic families. Public Health Nutr 17, 83-93.

23. Reat AM, Crixell SH, Friedman BJ et al. (2015) Comparison of food intake among infants and toddlers participating in a south central Texas WIC Program reveals some improvements after WIC package changes. Matern Child Health J 19, 1834-1841.

24. Dannefer R, Williams DA, Baronberg S et al. (2012) Healthy bodegas: increasing and promoting healthy foods at corner stores in New York City. Am J Public Health 102, 27-31.

25. Cavanaugh E, Mallya G, Brensinger C et al. (2013) Nutrition environments in corner stores in Philadelphia. Prev Med 56, 149-151.

26. Lent MR, Vander Veur S, Mallya G et al. (2015) Corner store purchases made by adults, adolescents and children: items, nutritional characteristics and amount spent. Public Health Nutr 18, 1706-1712.

27. Borradaile KE, Sherman S, Vander Veur SS et al. (2009) Snacking in children: the role of urban corner stores. Pediatrics 124, 1293-1298.

28. Kiszko K, Cantor J, Abrams C et al. (2015) Corner store purchases in a low-income urban community in NYC. J Community Health 40, 1084-1090.

29. Sharkey JR, Dean WR \& Nalty C (2012) Convenience stores and the marketing of foods and beverages through product assortment. Am J Prev Med 43, 3 Suppl. 2, S109-S115.

30. Farley TA, Rice J, Bodor JN et al. (2009) Measuring the food environment: shelf space of fruits, vegetables, and snack foods in stores. J Urban Health 86, 672-682.

31. Hollands GJ, Shemilt I, Marteau TM et al. (2013) Altering micro-environments to change population health behaviour: towards an evidence base for choice architecture interventions. BMC Public Health 13, 1218.

32. Thorndike AN, Sonnenberg L, Riis J et al. (2012) A 2-phase labeling and choice architecture intervention to improve healthy food and beverage choices. Am J Public Health 102, $527-533$.

33. Thorndike AN, Riis J, Sonnenberg LM et al. (2014) Trafficlight labels and choice architecture: promoting healthy food choices. Am J Prev Med 46, 143-149.

34. Hanks AS, Just DR \& Wansink B (2013) Smarter lunchrooms can address new school lunchroom guidelines and childhood obesity. J Pediatr 162, 867-869.

35. Skov LR, Lourenco S, Hansen GL et al. (2013) Choice architecture as a means to change eating behaviour in self-service settings: a systematic review. Obes Rev 14, 187-196.

36. Cummins S, Petticrew M, Sparks L et al. (2005) Large scale food retail interventions and diet. BMJ 330, 683-684.

37. Horowitz CR, Colson KA, Hebert PL et al. (2004) Barriers to buying healthy foods for people with diabetes: evidence of environmental disparities. Am J Public Health 94, 1549-1554. 
38. Cavanaugh E, Green S, Mallya G et al. (2014) Changes in food and beverage environments after an urban corner store intervention. Prev Med 65, 7-12.

39. Lent MR, Vander Veur SS, McCoy TA et al. (2014) A randomized controlled study of a healthy corner store initiative on the purchases of urban, low-income youth. Obesity (Silver Spring) 22, 2494-2500.

40. Song HJ, Gittelsohn J, Kim M et al. (2009) A corner store intervention in a low-income urban community is associated with increased availability and sales of some healthy foods. Public Health Nutr 12, 2060-2067.

41. Paek HJ, Oh HJ, Jung Y et al. (2014) Assessment of a healthy corner store program (FIT Store) in low-income, urban, and ethnically diverse neighborhoods in Michigan. Fam Community Health 37, 86-99.

42. Ortega AN, Albert SL, Sharif MZ et al. (2015) Proyecto Mercado FRESCO: a multi-level, community-engaged corner store intervention in East Los Angeles and Boyle Heights. J Community Health 40, 347-356.
43. Glanz K, Bader MD \& Iyer S (2012) Retail grocery store marketing strategies and obesity: an integrative review. Am J Prev Med 42, 503-512.

44. Escaron AL, Meinen AM, Nitzke SA et al. (2013) Supermarket and grocery store-based interventions to promote healthful food choices and eating practices: a systematic review. Prev Chronic Dis 10, E50.

45. Foster GD, Karpyn A, Wojtanowski AC et al. (2014) Placement and promotion strategies to increase sales of healthier products in supermarkets in low-income, ethnically diverse neighborhoods: a randomized controlled trial. Am J Clin Nutr 99, 1359-1368.

46. Andreyeva T, Middleton AE, Long MW et al. (2011) Food retailer practices, attitudes and beliefs about the supply of healthy foods. Public Health Nutr 14, 1024-1031.

47. Gittelsohn J, Laska MN, Karpyn A et al. (2014) Lessons learned from small store programs to increase healthy food access. Am J Health Behav 38, 307-315. 